\title{
Assessment of Customer Satisfaction in a Five Star Hotel - A Case Study
}

\author{
W. M. K. K. Karunaratne and L. N. A. C. Jayawardena ${ }^{1}$ \\ Postgraduate Institute of Agriculture \\ University of Peradeniya \\ Peradeniya, Sri Lanka
}

\begin{abstract}
Tourism industry has become one of the most profitable industries in the world. Customer satisfaction has been identified as a key performance indicator in hotel industry. This study focused on customer satisfaction of a five - star hotel in Kandy district. Servqual model was employed in the assessment of customer satisfaction of the hotel. The overall objective of this study was to examine the level of customer satisfaction and major factors contributing to customer satisfaction in a five star hotel. The data were collected using a questionnaire containing 49 questions based on 22 variables of the five dimensions of Tangibility, Reliability, Responsiveness, Assurance and Empathy. Sixty residential customers of the hotel were randomly selected. Focus group discussions and a perception survey among hotel staff were also conducted to enrich the findings. Data were analyzed using descriptive statistics, MINITAB Version 14 with Two Sample T-test. Majority of the customers expressed their satisfaction with the overall service they received from the hotel, especially regarding Tangibility, Responsiveness and Assurance. Findings revealed that the hotel had not fulfilled the customers' satisfaction with regard to Reliability and Empathy. It was note-worthy that a minority of customers felt overall dissatisfied with the service of the hotel. Customers seemed to have perceived the same service differently. Customers' expectations had been influenced by their knowledge about general standards of hotel practices.
\end{abstract}

\section{INTRODUCTION}

Customer satisfaction has become a key performance indicator for the hotel business. Customer demands and expectations are ever increasing and altering at a rapid rate in the hotel industry. During the recent decades, the tourism industry has become an effective source for monetary gains and economic growth. Achieving competitive advantages and high performance have been imperative for the success in hotel industry. Measurement of customer satisfaction is a note-worthy addition to the new ISO 9000:2000 standard. Organizations certified to this standard are now required to identify parameters that cause customer satisfaction and to consciously measure them. This study focused on the customer satisfaction of a five star hotel in Kandy district, Sri Lanka. A survey was carried out to assess the customer satisfaction employing Servqual model. The overall objective of this study was to examine the level of customer satisfaction and major factors contributing to customer satisfaction in the five star hotels. Specific objectives of the study were to identify the key areas of customer satisfaction, to analyze the major factors contributing to customer satisfaction and to assess customer satisfaction of facilities and services of the five star hotel selected for the study.

Dept. of Agric. Extension, Faculty of Agriculture, University of Peradeniya, Peradeniya, Sri Lanka 
There are several conceptual models which have been developed to evaluate customer satisfaction. From marketing perspective, customer satisfaction is achieved when the customer's needs and wants are fulfilled (Lam and Zhang, 1999). The aim of managing satisfaction is to obtain a higher rate of customer retention and to improve a company's market share and profits (Hessamaldin 2008). Parasuraman, et al., (1988) examined the applicability of the service dimensions to five services: appliance repair and maintenance, retail banking, long distance telephone service, securities brokerage, and credit cards. Five (5) service dimensions viz: Tangibility, Reliability, Responsiveness, Assurance and Empathy were identified, based on their analysis. Lam and Zhang, (1999) conducted a study to assess customers' expectations and perceptions of service quality, and identified a gap between the two. They also explored the impact of service quality factors on overall customer satisfaction. Their findings revealed that "Reliability", "Responsiveness" and "Assurance" were the most significant factors in predicting customers' satisfaction. These factors had the largest differential scores, indicating that customers' perceptions had been lower than their expectations. The purpose of measuring customer satisfaction is to assess the quality of the existing management practices and to identify directions for improvement. Given the growth of services during the last decades, many researchers have recognized the need to develop measures of service quality. One of the most frequently used measures is the SERVQUAL model based on determinants of perceived service quality (Parasuraman, et al., 1994). The model measures the difference between customers' expectations about general quality of a certain group of service providers and their perceptions about the actual performance of a service provider from that group. It uses a set of service quality determinants for gaps between service/ideal products and those perceived, separately for five fundamental dimensions (Tangibility, Reliability, Responsiveness, Assurance and Empathy). Many studies in different service industries have used this model as a basis of developing surveys to assess customer satisfaction.

SERVQUAL instrument is extensively used to assess external service quality. However, the instrument can also be modified to assess the quality of the internal services provided by departments and divisions of a company to its employees in other departments and divisions. Brysland and Curry (2001) found out in a study at a catering company, that organizations can at least assess five dimensions of service quality to ascertain the level of services provided, and determine which dimensions need improvement. The study emphasized the knowledge of customers' perception of the service quality and the ability to measure customer satisfaction which benefits industry professionals in numerous ways. The measurement of customer satisfaction could provide specific data that could be used in quality management. Cronin and Taylor (1994) have expressed their concerns of using the difference between customers' expectations and their perceived performance as a valid operational measure of service quality. In hotels, the tangible and intangible products are highly intertwined and have greater impact on guests' assessment of service quality (Alzaid and Soliman, 2002). Studies have emphasized that knowing how customers perceive service quality and being able to measure customer satisfaction can benefit industry professionals in quantitative and qualitative ways.

\section{MATERIALS AND METHODS}

Local and foreign customers who had stayed (at least overnight) at the selected five star hotel, located in Kandy district, (hereinafter referred to as the Hotel), during the months of February and March 2009, was the population for the study. They were estimated to be about 3,000 and the total employees of the Hotel was 204. Pre-testing of the questionnaire was 
conducted with ten customers. Sixty local and foreign customers were selected from those who were available for the study based on random sampling. The major data collection tool was a questionnaire, developed using a five point (1 to 5) Likert scale, elaborating 22 variables based on the five dimensions of SERVQUAL model (Table 1). The demographic data of customers (age, gender, nationality, education level, mode of reservation and purpose of visit) were collected during the interviews. The questionnaire was designed to provide an assessment of the gap between the desired and actual performance (experienced), together with a ranking of the importance of service criteria. Five focus group interviews were conducted using groups of 6-10 people who provided instant feedback on service issues and levels of customer satisfaction. Data were analyzed using descriptive statistics, MINITAB Version 14 with Two Sample T- tests. Descriptive statistics such as frequencies, percentages and averages were employed.

Table 1. The five key dimensions of SERVQUAL model and the variables.

\begin{tabular}{ll}
\hline Dimension & \multicolumn{1}{c}{ Variables } \\
\hline Tangibility & $\begin{array}{l}\text { Attractiveness (external ), Internal decorations, Staff appearance } \\
\text { \& tidiness, Hotel facilities } \\
\text { Timely accommodation, Rooms delivered to customers, }\end{array}$ \\
Reliability & $\begin{array}{l}\text { Facilities of rooms, Orders done by staff } \\
\text { Responsiveness }\end{array}$ \\
& $\begin{array}{l}\text { Welcoming of customers, Response for requests, Giving } \\
\text { information offering for service, Speed of service } \\
\text { Staff experience and professionalism, Staff politeness, Price of } \\
\text { service, Effort done by staff for security, Hotel atmosphere(calm }\end{array}$ \\
Empathy & $\begin{array}{l}\text { and quit) } \\
\text { Accessibility, Staff availability, Attention paid by staff, Staff } \\
\text { flexibility, Hotel prevision for customer necessities }\end{array}$ \\
\hline
\end{tabular}

\section{RESULTS AND DISCUSSION}

\section{Customer profiles}

Forty percent of the customers were women. Majority of the customers were below 40 years of age. However, there were nearly $17 \%$ of customers above the age of 56 years. Among the interviewed customers, majority $(66.7 \%)$ had qualification up to diploma level in their respective fields while $20 \%$ customers had qualification up to postgraduate level. Customers consisted of eight nationalities and the highest proportion of customers $(43.3 \%)$ was from Middle East countries. Majority $(68.3 \%)$ of the customers had visited for recreation and leisure, whilst $31.7 \%$ had visited for business purposes. It was note-worthy that almost all the Middle East customers had visited for business purposes. Majority of the customers had made their reservations through travel agencies (73.3\%), whilst others had personal arrangements. Almost all local customers had personally reserved the Hotel and most of the foreign customers had come through travel agencies such as Aitken Spence, Jetwing and Ferien Lanka Tours.

\section{Dimensions of customer satisfaction}

The null hypothesis tested for the study was that the customers were dissatisfied as their perceptions of hotel, and facilities (experienced) were below their expectations. Customers' expectations and perceptions on Tangibility dimension were sought on four variables (Table 
2). Customers were asked seventeen questions to verify their level of expectations and perceptions on the above variables.

Table 2. Cumulative average rating (CAR) for the five key dimensions in SERVQUAL model, and their variables.

\begin{tabular}{|c|c|c|c|c|}
\hline \multirow{2}{*}{ Dimension } & \multirow{2}{*}{ Variables } & \multicolumn{2}{|c|}{ CAR } & \multirow{2}{*}{$\frac{\mathrm{CS}^{* * * *}}{(\mathrm{P}-\mathrm{E})}$} \\
\hline & & $\mathbf{E}^{*}$ & $\mathbf{P} * *$ & \\
\hline \multirow{4}{*}{ Tangibility } & Attractiveness (external ) & 4.6 & 4.7 & +0.1 \\
\hline & Internal decorations & 4.4 & 4.6 & +0.2 \\
\hline & Staff appearance $\&$ tidiness & 4.7 & 5.0 & +0.3 \\
\hline & Hotel facilities & 4.0 & 4.1 & +0.1 \\
\hline \multirow{4}{*}{ Reliability } & Timely accommodation & 4.9 & 4.5 & -0.4 \\
\hline & Room delivered to customers & 4.9 & 5.0 & +0.1 \\
\hline & Facilities of rooms & 4.8 & 4.9 & +0.1 \\
\hline & Orders done by staff & 4.6 & 4.4 & -0.2 \\
\hline \multirow{4}{*}{ Responsiveness } & Welcoming of customers & 4.7 & 4.9 & +0.2 \\
\hline & Respond for requests & 4.8 & 4.7 & -0.1 \\
\hline & Giving information offering for service & 4.8 & 4.8 & 0 \\
\hline & Speed of service & 4.7 & 4.8 & +0.1 \\
\hline \multirow{5}{*}{ Assurance } & Staff experience and professionalism & 4.7 & 4.9 & +0.2 \\
\hline & Staff politeness & 4.7 & 4.7 & 0 \\
\hline & Price of service & 4.8 & 4.8 & 0 \\
\hline & Effort done by staff for security & 4.9 & 5.0 & +0.1 \\
\hline & Hotel atmosphere(calm) & 4.6 & 5.0 & +0.4 \\
\hline \multirow{5}{*}{ Empathy } & Accessibility & 4.8 & 4.4 & -0.4 \\
\hline & Staff availability & 4.9 & 4.9 & 0 \\
\hline & Attention paid by staff & 4.3 & 4.5 & +0.2 \\
\hline & Staff flexibility & 4.3 & 4.0 & -0.3 \\
\hline & Hotel prevision for customer necessities & 4.2 & 4.1 & -0.1 \\
\hline \multicolumn{4}{|c|}{ Cumulative Average Rating (CAR) } & +0.30 \\
\hline
\end{tabular}

Staff appearance scored the highest Cumulative Average Rating (CAR) which was 5.0/5.0 (that is $100 \%$ ), both for customers' expectations and perceptions. The least CAR was for the availability of indoor games, for expectations and perceptions both, with CARs of 3.6 and 3.7 (out of 5.0), respectively. Overall CAR for customer perception on Tangibility dimension was higher than that of expectation. That is, customers' expectations based on Tangibility dimension had been met. Other reasons for customers' satisfaction were the hotel features viz: attractive buildings, new decorations, and staff consisting of young and disciplined personnel to serve the customers. Focus group discussions revealed that some respondents had been particularly pleased with facilities with remarks such as "pleasant surrounding, fabulous location, great rooms, green and tropical surrounding, relaxing pool etc." In addition, some customers suggested few improvements as well. A positive difference (of +0.184 ) between perceptions and expectations of the customers related to the Tangibility dimension was recorded. Accordingly, customers were satisfied with the Tangibility dimension of the Hotel. 
Customers' expectations and perceptions on the Reliability dimension of the Hotel were sought based on four variables (Table 1). Customers were asked eleven questions to ascertain their level of expectations and perceptions on the above variables. The highest CAR of the answer scores for expectations were related to hotel operating hours and space capacity of rooms. The highest CAR of answer scores of customers' perception on Hotel Reliability related to the five areas viz: convenient hotel operating hours, space capacity of rooms, location and external environment, quality of toilets, and quality of furniture. The CAR for this category was the maximum of five (5.0). The least CAR of the answer scores of Reliability dimension for both expectations and perceptions was on timely delivery of service with rates of 4.3 and 4.1 (out of 5), respectively. Most of the customers were in a hurry in morning check-outs and needed to have their breakfast soon. Customers' expectations on the availability of facilities in the hotel shopping arcade, condition of swimming pool, restaurant services, availability of the exercise equipments and sports facilities, availability of indoor games, guided tours/ excursions arranged by the hotel, and reliable reservation system had not been met. Overall satisfaction on Reliability dimension of Hotel was below customer expectations. As per SERVQUAL model, service quality of Reliability was rated at -0.023 . This confirmed customer dissatisfaction on Reliability dimension of Hotel. Comments from the focus group discussions verified the lack of paying attention to detail, with regard to specific socio-cultural needs of customers and few customers were dissatisfied with hotel operating hours and on-time delivery service. In Reliability dimension, a shortfall between customer expectations and perceptions was found. However, many customers were satisfied about space capacity of rooms and room equipments.

Customers' expectations and perceptions were sought on four variables coming under the Responsiveness dimension (Table1). Customers were asked eight questions to ascertain their level of expectations and perceptions on the above variables. The highest CAR was related to customers' expectation on the quality of food and beverage which was 4.9. However, the customers' perception of the quality of food and beverage recorded the lowest CAR. Many local customers were not satisfied about the variety of foods and their quality. The least CAR of the answer score (4.7) for customers' expectation was related to the greeting and welcoming of guests, efficiency of check-in/check-out, response to customer needs and availability of indoor games. Greeting and welcoming of guests was the highest in customer perceptions, which was 5.0. This positive difference had been mainly due to the welcoming of customers in a customized manner and orienting them to different services rendered by the Hotel. Most of the customers, in focus group discussions, had mentioned about the importance of information counter, travel desk or ticketing counter. Customers pointed out instances where the desk staff had forgotten to inform customers of charges for some services. At check-out, customers had complained that they were 'kept in the dark' of some Hotel charges. It seemed that hotel management needed to pay more attention to this. The CAR of customer expectations and perceptions with regard to the Responsiveness of Hotel recorded a

positive difference of 0.054 . It showed that the customers' perception was higher than their expectations.

Customers' expectations and perceptions on Assurance dimension of the Hotel were sought on five variables (Table1). They were examined through ten questions to verify their level of expectations and perceptions on the above variables. The highest CAR of the answers for customers' expectations was related to the security arrangements, which was 4.9 and the lowest was for quietness and calmness which was 4.6. With regard to the perceived services, 
the highest CAR of 5.0 was related to staff trustworthiness, modes of payment, quietness and calmness, and security arrangements. The lowest CAR of 4.7 was recorded for value for money of the Hotel services, and staff politeness. In addition, customers' comments from the focus group discussions emphasized that most of them were dissatisfied with Hotel atmosphere. Customers expressed dissatisfaction regarding the noise level within the Hotel environment. They have mentioned of noise disturbances from outside the Hotel rooms in the early morning, presumably from hotel housekeeping staff in the corridors just outside of the rooms. A positive difference $(+0.122)$ was observed with regard to the customers' perceptions and expectations of the Assurance dimension. It confirmed that customers' expectations had been met and they were satisfied about the Assurance dimension of Hotel services.

Customers' expectations and perceptions on Empathy dimension of Hotel were sought on five variables. Customers were asked five questions to ascertain their level of expectations and perceptions on those variables (Table1). The highest CAR of 4.9 related to the availability of staff, for both expectations and perceptions. The least CAR, of 4.0 was related to the customers' expectations on the sensitivity to demands and flexibility of Hotel staff. A negative difference (-0.027) on the dimension of Empathy was noted between the customers' expectations and perceptions. As per the SERVQUALl model, service quality in this dimension was slightly sub-standard. It showed that the customers' perception was lower than their expectation and they had been dissatisfied with the Empathy dimension of the Hotel. Few customers had expressed dissatisfaction with accessibility and location of the Hotel in focus group discussions. This was mainly due to the Hotel being far outside of the city centre and customers needed transport facility to visit the city centre for several purposes such as saloons and banks.

\section{Overall satisfaction}

Table 3. Summary of the customers' expectations and their perceptions on Hotel services based on the five dimensions in SERVQUAL model.

\begin{tabular}{lccc}
\hline Five Dimensions & $\begin{array}{c}\text { CAR of Customers' } \\
\text { Expectations } \\
(\mathbf{E})\end{array}$ & $\begin{array}{c}\text { CAR of Customers' } \\
\text { Perceptions } \\
(\mathbf{P})\end{array}$ & $\begin{array}{c}\text { Customers' } \\
\text { Satisfaction } \\
\text { (P-E) }\end{array}$ \\
\hline Tangibility & 4.460 & 4.644 & +0.184 \\
Reliability & 4.799 & 4.776 & -0.023 \\
Responsiveness & 4.817 & 4.869 & +0.052 \\
Assurance & 4.795 & 4.917 & +0.122 \\
Empathy & 4.430 & 4.403 & -0.027 \\
& Cumulative Average Rating (CAR) & $\mathbf{0 . 3 0 8}$ \\
\hline
\end{tabular}

Customers were happy with the service dimensions of Tangibility, Responsiveness and Assurance of the Hotel. As shown in Table 3, the negative sign of CAR scores between the perceptions and expectations of the customers indicated a negative difference in Reliability and Empathy dimensions. Hotel had not been capable of fulfilling the customers' satisfaction in Reliability and Empathy dimensions. Empathy dimension with a difference of -0.027 has recorded the highest level of customer dissatisfaction. Hotel Tangibility dimension with a score of +0.184 recorded the highest level of customer satisfaction. 


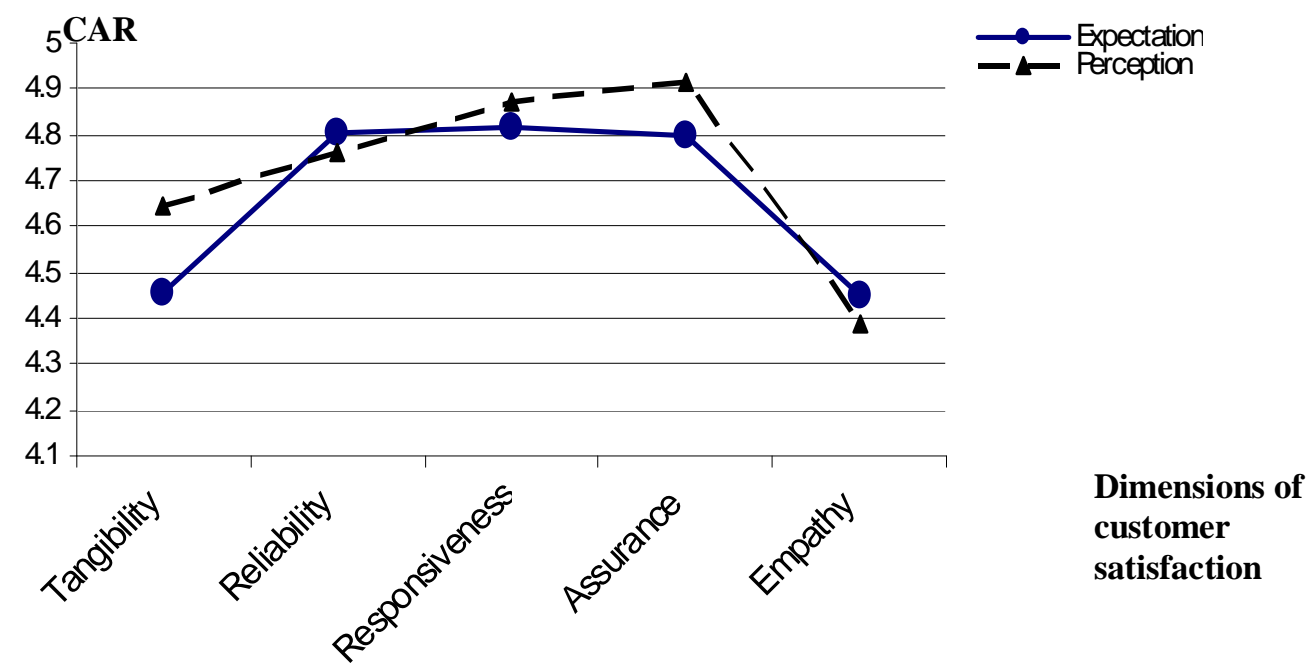

Fig. 1. Levels of expectations and perceptions of services based on five dimensions of customer satisfaction.

As per the five dimensions of SERVQUAL model, the overall positive value of 0.30 indicated that the customers were satisfied with the overall service of the hotel. At the end of the interviews, customers were separately asked of their overall satisfaction with regard to the hotel facilities and services. The CAR of their responses was 3.31 out of 5.0. This drop in CAR would also have been a result of absence of some facilities and service dimensions which were not covered in SERVQUAL.

As shown in Fig. 1, customers' expectations and demand for service dimensions seemed to be matching in the perception curve. Because of the relativity of the service quality dimension, it could well be compared with prior experiences, of other hotel customers who have stayed in before. Customers' expectations can differ according to their individual (prior) experiences and comparisons with the background of other hotels. The majority of customers had expressed their satisfaction of the overall services that they received (experienced) at the Hotel. However, a minority of customers had felt fairly dissatisfied with services of the Hotel.

\section{CONCLUSION}

Five dimensions of service quality of the Hotel were tested in the study. The majority of customers had expressed their satisfaction with the overall service that they received from the Hotel, especially regarding Tangibility, Responsiveness and Assurance. Customers expressed their dissatisfaction with the service dimensions of Reliability and Empathy of the Hotel services. However, there were few customers who had felt overall dissatisfied with the Hotel services. The information on service quality gaps could help managers to diagnose where performance improvement can best be targeted.

The largest negative gap, combined with the assessment of where expectations are the highest, facilitates prioritization of performance improvement. Hotel managers had seemingly specified the frequency of distribution of customers upon considering age, gender, 
nationality, education level, way of room reservation and other specifications obtained through periodical evaluations in their Hotel to meet the satisfaction of customers on the basis of their needs, culture and interests. The results of the study showed that the hotel was not capable of fulfilling the customers' satisfaction with regard to Reliability and Empathy dimensions of Hotel services. Perception of quality seemed not stable and often changeable based on different and varying needs and wants of customers. Hotel services had impacted customers differently. In other words, customers seemed to have perceived the same service differently. Customers' culture, religious practices and knowledge would have had an impact on this. Expectations had been influenced by the knowledge of customers about general standard of Hotel's practices. The highest numbers of customers were from Middle East countries, and most of them were Muslims. Hotel staff lacked the familiarity of knowledge of other cultural and religious practices. Culture of customers seems to be a major factor that the hotel industry should consider in order to improve its services in this context. Hotel management needs to pay more attention to improve the service quality with regard to the dimensions of Reliability and Empathy of customers. To reach the above aim and to uplift the service standards, the hotel management could set proper standards and support them with resources and facilities (training \& development, advanced technology and system support etc) and practice effective internal communication to establish a service culture in the organization. Identification of the service bottle-necks itself lead to facilitate changes for improvement.

\section{ACKNOWLEDGEMENT}

Authors wish to acknowledge the support given by the management and service staff of the selected Hotel, in data collection and providing information.

\section{REFERENCES}

Alzaid, A.A. and Soliman, A.A. (2002). Service quality in Riyadh's Elite hotels: measurement and evaluation. J. King Saud. Univ. Admin. Sci 14(2): 83-103.

Brysland, A. and Curry, A. (2001), "Service improvements in public services using SERVQUAL". Managing Service Quality, 11(6): 389-401.

Cronin, J.J. and Taylor, S. A. (1994). SERVPERF versus SERVQUAL: reconciling performance-based and perceptions- minus-expectations measurement of service quality. J. Market. 58: 125-131.

Hessamaldin, M.S. (2008). Customer Satisfaction in Four Star Isfahan Hotels, An Application of SERVQUAL Model. Master's Thesis. Lulea University of Technology, Iran.

Lam, T and Zhang, H. (1999). Service quality of travel agents: the case of travel agents in Hong Kong. Tourism Magt. 20: 341-349.

Parasuraman, A., Zeithaml, V.A. and Berry, L.L. (1994). Reassessment of expectations as a comparison standard in measuring service quality: implications for future research. J. Market., 58: 111-124.

Parasuraman, A. Zeithaml, V. A. and Berry, L.L.(1988). Servqual; A multiple-item scale for measuring consumer perception. J. Retailing, 64(1): 12. 